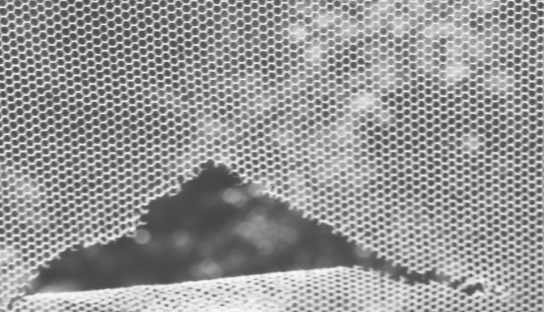

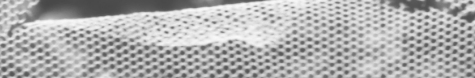

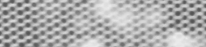

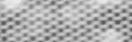


'Ball of Plastic Foill' by Leo Schatzl; essay by Marlies Scheuchenegger. 


\section{Artist's Gaze and Zero Waste: Materiality and Value}

\section{Marlies Scheuchenegger}

There is one aspect of the art world that I find fascinating, and that is the question of what counts as waste - it opens questions that are one hand theoretical, while on the other hand also being practical, material as well as social. The Austrian artist with whom I worked, Leo Schatzl, has a very interesting and unique view of things; he defines his way of doing arts as a new interpretation of space and keeps an eye on the reactions of the audiences. His aim is to achieve multilayered artworks that can fit more than one purposes; e.g. the work 'Hoher Zaun' (Tall Fence) in Laa an der Thaya/former Iron Curtain, which opens a space for reflection about the border, while reversing the very function of a border fence. His current work 'loose harbour' acts as a sculpture, as a space for social interaction and on another level, changes its surroundings as well (first presented on the 2017/09/16 at the Space of Verein Symposion Lindabrunn). Leo Schatzl has an exceptionally grounded view on the different aspects of his life as an artist; this is a result of his lifelong experience. He sees the changes he went through in the course of his career and understands how these still impact his current work. When asked about his definition of waste in the context of art, Leo rejected the term on the grounds of his personal relation to an object. Even if not used in the further process, there is a special attachment to it, and Leo tries to find a new purpose for this particular item at a later date and more often than not, in an entirely different context. Interestingly, this thinking does not stem from any environmental considerations (though these are a nice byproduct), but solely from the desire not to turn something into waste. The reason for this mindset, Leo finds in the generation he belongs to; when people at least tried to repair items before throwing them out. During his studies in Upper Austria, he had the chance to gather some of the items he needed in an enterprise's dump. He often came up with new ideas for a specific item while collecting them; so, this opened a new opportunity for him, not only on the material level but also on a creative one. Amusingly, a lot of those items found their way back into the dump, for others to find them.

"Waste is mostly seen as "goods that a person wants to get rid of", even when still functional' (Stegmann/ van der Westhuyzen 2014). With this approach, I want to introduce the ball of wrapping plastic. For me this transparent wrapping plastic rolled into a semi-big ball represents the clearest form of waste. It was used to protect an art work, that was displayed in an exhibition, from scratches and minor destruction and was meant to be thrown away after usage. Leo Schatzl started to make a ball out of it out of some reason he cannot make out anymore. Holding this compact item in his hands, he decided to keep it and reuse it in some other, not yet fixed context. Even though one would not normally define a ball of plastic foil as art and/or functional, having the background knowledge about Leo Schatzl, it makes perfect sense to increase the significance of this piece. In this respect, the question arises whether the artist or the audience is giving the meaning and value to an object; in a beauty-lies-in-the-eye-of-thebeholder manner. Here I want to invoke another work of art by Leo; the 'Tabu Zone'. The general concept was to select a random, around $1.000 \mathrm{~m}^{2}$ big area in the nature of Upper Austrian Münzbach, build a fence around it and shape it as a zone free of all 
cultural influences for the next five years. The underlying idea for this project is shaped by the belief that people are reaching for a higher quality of life by adding as much as possible and that it would be much more interesting to build a space which reverses this logic, that is a space free of the exhausting hoarding people seem to fall for in order to reach the ultimate goal of happiness. Leo wanted to take a step back and open up a new angle.

The reaction of the audience to the 'Tabu Zone' became an important part in a later review of the project. In the search for a deeper understanding, the audiences started to theorise and search for the true meaning of Leo's work; 'Maybe it's a statement om environmental issues', 'What is the surplus to this?' Leo made sure that everyone understood that it is solely about creating a cultural vacuum and therefore defined the true meaning of this artwork himself. I think this is interesting and important to mention because it gives the strength to frame the work back to the artist and raises more question in this direction. In combination with value-creation, one can ask whether the audience's opinion is significant, whether art is valuable when the audience accepts it or even determines if it counts as one. But in our concept, the artwork is seen as waste and is given value through the artist's eye; the artist's gaze so to speak. During this process, a useless object acquires a new purpose. In the case of the ball of wrapping plastic, it seems clear that the artist has the power to enhance the meaning of a simple, thin, transparent plastic foil to a potential art work. 'Upcycling is an emerging trend whereby one sees value in both the composition and the form of an object but not the intention' (Szaky 2014). In the act of rolling it, the value and meaning changes in the artist's eye and it becomes his concern to find a new form for it to make others understand why he kept it and why he values it.

Here the concept of 'zero waste' begs mentioning, it aligns perfectly with recycling and upcycling. 'The key difference between upcycling and reusing waste is that with upcycling the original intention of the object changes' (Szaky 2014). So to recycle the ball would mean to keep it and wrap it around some artworks again at a later date; upcycling opens much more possibilities. For creative people, it can be a way to stimulate an open and new approach to an almost infinite amount of materials and add a new level of value to forgotten goods. For Leo Schatzl it is a personal attachment, for others, it is an environmental consideration, or something different - maybe the need to clean out a storage unit. We have tried to raise several questions regarding valuation, meaning-making and zero waste, as well as micro-processes that change one's perspective of certain objects framed as waste and to open our eyes to the multilayered, seemingly endless possibilities to those items. In a time when people tend not to have any significant attachment to things, it was refreshing to be able to talk with someone who values exactly that. This being said, I am looking forward to finding out in which context the ball of wrapping plastic will find its new purpose.

Tom Szaky. 2014. Outsmart Waste: The Modern Idea of Garbage and How to Think Our Way Out of It, San Francisco: Berrett-Koehler Publisher.

Rainer Stegmann and Cristina van der Westhuyzen. 2014. 'From waste to artThe IWWG Art Gallery,' Waste Management 34/5: 845-847.

Interview with Leo Schatzl (2017/05/14): 1:01:11. 